\title{
Correction to: India's lockdown: an interim report
}

\author{
Debraj Ray ${ }^{1} \cdot$ S. Subramanian ${ }^{2}$
}

Published online: 28 September 2020

(c) Editorial Office, Indian Economic Review 2020

\section{Correction to: Indian Economic Review https://doi.org/10.1007/s41775-020-00094-2}

In the original publication of this article, the author's affiliation is incorrect.

For the second named author S. Subramanian, the author's affiliation should be that of 'Independent Researcher, Chennai, India'.

The error is regretted.

Publisher's Note Springer Nature remains neutral with regard to jurisdictional claims in published maps and institutional affiliations.

The original article can be found online at https://doi.org/10.1007/s41775-020-00094-2.

Debraj Ray

debraj.ray@nyu.edu

S. Subramanian

ssubramanianecon@gmail.com

1 New York University and University of Warwick, New York, USA

2 Independent Researcher, Chennai, India 